Wojciech J. Nowak*, Bartek Wierzba and Jan Sieniawski

\title{
Effect of Ti and Ta on Oxidation Kinetic of Chromia Forming Ni-Base Superalloys in $\mathrm{Ar}-\mathrm{O}_{2}$-Based Atmosphere
}

https://doi.org/10.1515/htmp-2017-0089

Received June 23, 2017; accepted October 30, 2017

\begin{abstract}
In the present study, two commercially available Ni-base superalloys, namely Rene 80 which contains $\mathrm{Ti}$ and IN 792 containing $\mathrm{Ti}$ and $\mathrm{Ta}$, were investigated during isothermal oxidation at $1,050^{\circ} \mathrm{C}$ in $\mathrm{Ar}-20 \% \mathrm{O}_{2}$ gas up to 50 h. It was found that IN 792 showed a slightly lower oxidation rate as compared to Rene 80 . Also differences in oxide scale microstructures and thicknesses were found. Both alloys formed qualitatively similar oxide scales consisting of outer $\mathrm{TiO}_{2}$ on top of a $\mathrm{Cr}_{2} \mathrm{O}_{3}$ scale and internally oxidized $\mathrm{Al}_{2} \mathrm{O}_{3}$. The IN 792 formed a thinner oxide scale in general as well as a thinner outer $\mathrm{TiO}_{2}$ scale. Also the depth of the internally oxidized $\mathrm{Al}_{2} \mathrm{O}_{3}$ precipitates is smaller in case of IN 792. These findings were correlated with the formation of $\mathrm{TiTaO}_{4}$, which in turn hampered outer $\mathrm{Ti}$ and inward oxygen flux.
\end{abstract}

Keywords: Ni-base superalloy, high-temperature oxidation, alloying elements effect

PACS $^{\circledR}$ (2010). 81.65.Mq Oxidation

\section{Introduction}

In stationary gas turbines (SGTs) as well as in aircraft engines, Ni-based superalloys are commonly used as construction materials. These alloys can be used in load-bearing applications at about $80 \%$ of their melting temperature [1]. Moreover, the materials used in the hot sections of the gas turbines have to fulfil a number of requirements, such as suitable ductility at low temperature, high creep strength and high oxidation resistance in a wide temperature range.

*Corresponding author: Wojciech J. Nowak, Department of Materials Science, Faculty of Mechanical Engineering and Aeronautics, Rzeszow University of Technology, al. Powstancow Warszawy 12, 35-959 Rzeszow, Poland, E-mail: w.nowak@prz.edu.pl

Bartek Wierzba, Jan Sieniawski, Department of Materials Science, Faculty of Mechanical Engineering and Aeronautics, Rzeszow University of Technology, al. Powstancow Warszawy 12, 35-959 Rzeszow, Poland
During high-temperature exposure, oxidation products start to form at the interface between metal and the surrounding atmosphere. This fact leads to changes in the local chemical composition of the alloy in the region below the oxide scale due to the consumption of the alloying elements during reaction with the environment. These changes of chemistry might cause changes in the local alloy microstructure. After formation of a continuous oxide scale, the reaction products become separated from the environment and the oxidation rate is controlled by solid-state diffusion through the oxide according to the mechanisms described by Wagner [2]. To investigate the oxidation kinetics, thermogravimetrical analyses are widely used [3]. Depending on the chemistry, Ni-base alloys can be classified as a $\mathrm{NiO}$, $\mathrm{Cr}_{2} \mathrm{O}_{3}$ or $\mathrm{Al}_{2} \mathrm{O}_{3}$ forming alloys [4]. The growth rate of $\mathrm{NiO}$ is relatively high [5], while $\mathrm{Cr}_{2} \mathrm{O}_{3}$ and $\mathrm{Al}_{2} \mathrm{O}_{3}$ are claimed to be protective oxide scales due to their relatively slow growth rate; therefore their formation on the alloy surface is desired [6]. The Ni-base superalloys possess excellent mechanical properties due to their microstructure: a fine precipitate of strengthening phase $y^{\prime}-\mathrm{Ni}_{3} \mathrm{Al}$ homogeneously distributed in a $y$-Ni matrix. The strengthening phase $y^{\prime}-\mathrm{Ni}_{3} \mathrm{Al}$ is stabilized by the addition of alloying elements, like $\mathrm{Al}, \mathrm{Ti}$, Ta and $\mathrm{Nb}$ [1]. However, it is known from the literature that the alloying elements might influence the growth rate of the oxide scales, like $\mathrm{NiO}$ [7] or $\mathrm{Cr}_{2} \mathrm{O}_{3}$ [8]

The aim of the present work is to investigate the effect of the $\mathrm{y}^{\prime}$-stabilizers, $\mathrm{Ti}$ and $\mathrm{Ta}$, on oxidation kinetics and scale formation on the commercially available Ni-based superalloys IN 792 and Rene 80 during exposure at $1,050{ }^{\circ} \mathrm{C}$ in $\mathrm{Ar}-20 \% \mathrm{O}_{2}$ atmosphere. The $\mathrm{Ar}-$ $20 \% \mathrm{O}_{2}$ gas has been chosen instead of synthetic air to avoid TiN precipitation below the oxide scale, thus not hampering Ti transport over the scale and its oxidation.

\section{Experimental}

The oxidation behaviour of two commercially available chromia forming Ni-base superalloys, namely Rene 80 and IN 792, with the nominal compositions shown in Table 1 and similar grain size of about $100-200 \mu \mathrm{m}$ was 
Table 1: Nominal chemical composition of studied alloys given in wt\%.

\begin{tabular}{|c|c|c|c|c|c|c|c|c|c|c|c|c|}
\hline \multirow[t]{2}{*}{ Name of the alloy } & \multicolumn{12}{|c|}{ Elements (wt\%) } \\
\hline & $\mathrm{Ni}$ & $\mathrm{Cr}$ & $\mathrm{Ta}$ & Co & Mo & $\mathbf{w}$ & Al & $\mathrm{Ti}$ & $\mathrm{Zr}$ & B & $\mathrm{Fe}$ & C \\
\hline Rene 80 & BASE & 14.00 & - & 9.50 & 4.00 & 4.00 & 3.00 & 5.00 & 0.03 & 0.02 & - & 0.16 \\
\hline IN 792 & BASE & 12.50 & 4.00 & 8.90 & 1.90 & 4.00 & 3.40 & 4.00 & 0.02 & 0.02 & 0.20 & 0.08 \\
\hline
\end{tabular}

investigated in the present work. From both materials, rectangular coupons with the dimensions $20 \times 10 \times 2 \mathrm{~mm}$ were machined and prepared by grinding up to 1,200 grit surface finishing. Isothermal oxidation tests were performed using Setaram TGA 92-16.18 thermobalance. The tests were performed at $1,050{ }^{\circ} \mathrm{C}$ up to $50 \mathrm{~h}$ in $\mathrm{Ar}-20 \% \mathrm{O}_{2}$. The heating rate was $90 \mathrm{~K} / \mathrm{min}$, the cooling rate was 10 $\mathrm{K} / \mathrm{min}$ and the gas flow rate was $21 / \mathrm{h}$.

Prior to cross-section preparation, samples were investigated by glow discharge-optical emission spectrometry (GD-OES). The GD-OES depth profiles were quantified using the procedure described in references [9-11]. The sputtering time was converted into depth by measuring the total crater depth after analysis and assuming equal sputtering rate of the oxide scale and the alloy. For crosssection preparation, oxidized specimens were cut in the middle, sputtered with a very thin gold layer using cathodic evaporation, electrolithycally coated with nickel and mounted in resin. Metallographic cross-sections were prepared by a series of grinding and polishing steps, finishing with a fine polishing in $\mathrm{SiO}_{2}$ suspension with $0.25 \mu \mathrm{m}$ granulation. The cross-sections were analysed using optical and scanning electron microscopy (SEM).

\section{Results and discussion}

Figure 1 shows the SEM images of the cross-sections of the studied alloys in the as-received condition. It is visible that both alloys reveal $y-y$ ' structure; however, in IN 792 eutectic regions are present, while in Rene 80 such a microstructure is not observed. In contrast to IN 792, Rene 80 possesses carbides in the microstructure, which can be correlated with the higher carbon content in Rene 80 as compared with IN 792 (see Table 1). A similar microstructure was observed and described by Nowak et al. [12].

The mass changes obtained for the studied alloys during isothermal oxidation at $1,050{ }^{\circ} \mathrm{C}$ for $50 \mathrm{~h}$ in $\mathrm{Ar}-$ $20 \% \mathrm{O}_{2}$ are shown on Figure 2. One can observe a slightly higher mass gain for the alloy Rene 80 (about $3.0 \mathrm{mg} \cdot \mathrm{cm}^{-2}$ ) compared to IN 792 for which the mass gain after $50 \mathrm{~h}$ exposure is about $2.5 \mathrm{mg} \cdot \mathrm{cm}^{-2}$. The plot showing the instantaneous apparent parabolic rate constant $k^{\prime}{ }_{w}$ revealed a small drop of the oxidation kinetics of IN 792 after about $18 \mathrm{~h}$ of exposure (Figure 3). Both mass change and $k^{\prime}{ }_{w}$ values obtained for the alloy Rene 80 investigated in the present work are comparable to the values obtained during exposure at $1,050^{\circ} \mathrm{C}$ for $50 \mathrm{~h}$ in synthetic air [12].

According to the oxidation map by Giggins and Pettit [4], both alloys are classified to be marginal alumina formers if only the elements $\mathrm{Ni}, \mathrm{Cr}$ and $\mathrm{Al}$ are considered (see Figure 4). GD-OES analysis of the alloys after isothermal oxidation tests revealed that both alloys did not form alumina- but rather chromia-based oxide scale (Figures 5 and 6). GD-OES depth profile of Rene 80 (Figures $5 \mathrm{a}$ and $\mathrm{b}$ ) revealed the enrichment of $\mathrm{Ti}$ in the very outer part of the oxide scale, below which a wide
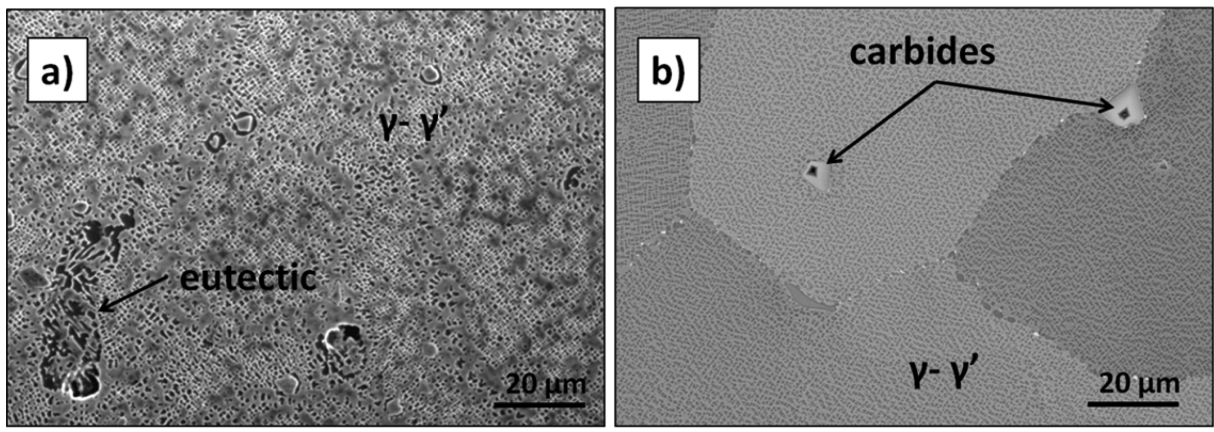

Figure 1: SEM images showing the microstructures of the cross-section of: (a) IN 792 and (b) Rene 80 in the as-received condition. 


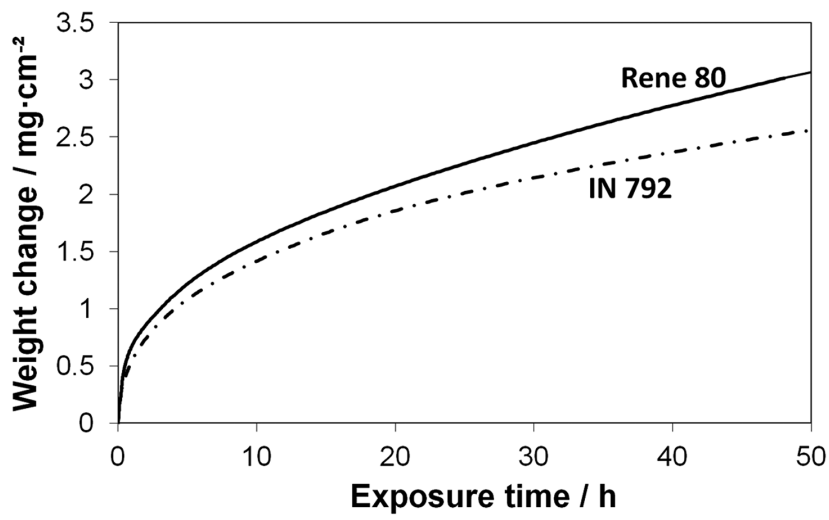

Figure 2: Mass gain plot obtained during isothermal oxidation of Rene 80 and IN 792 at $1,050^{\circ} \mathrm{C}$ for $50 \mathrm{~h}$ in $\mathrm{Ar}-20 \% \mathrm{O}_{2}$.

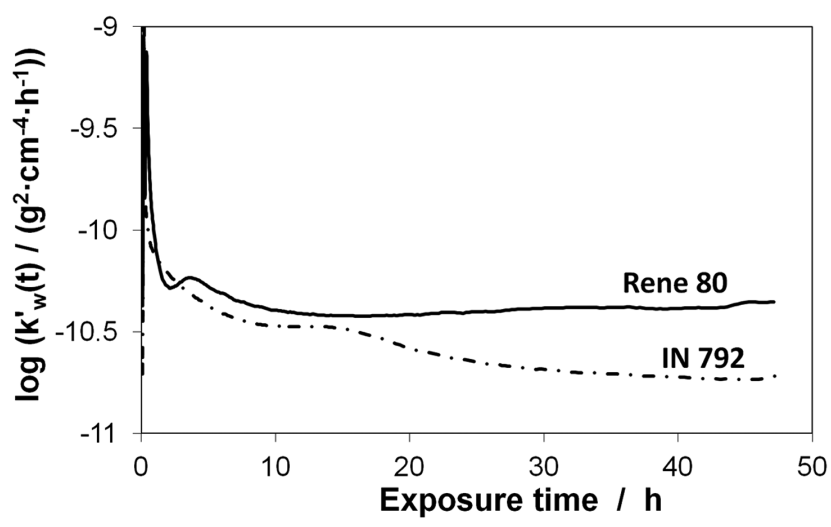

Figure 3: Instantaneous parabolic rate constant $k_{w}$ calculated using data according to the procedure described in $[13,14]$.

zone of $\mathrm{Cr}$ enrichment is present. At the bottom part of the oxide scale, enrichment of boron is visible. At about $30 \mu \mathrm{m}$ depth, a peak of aluminium is present. Qualitatively, the GD-OES depth profile of Rene 80 investigated in the present study is similar to that of the same material exposed to synthetic air studied by Jalowicka et al. [15] and Nowak et al. [12]. However, the enrichment of boron in the present study is smaller and no enrichment of nitrogen is observed in the present study as compared to the observations by Jalowicka etal. [15] and Nowak etal. [12]. As observed by Jalowicka et. al [8], Ti in Rene 80 will not form a continuous layer of TiN as found by Kanjer et al. [16]. Therefore, it will not influence substantially diffusion of the alloying elements, but it will rather form TiN precipitates below the oxide scale; therefore, part of the Ti which could be oxidized will be consumed to form stable TiN.

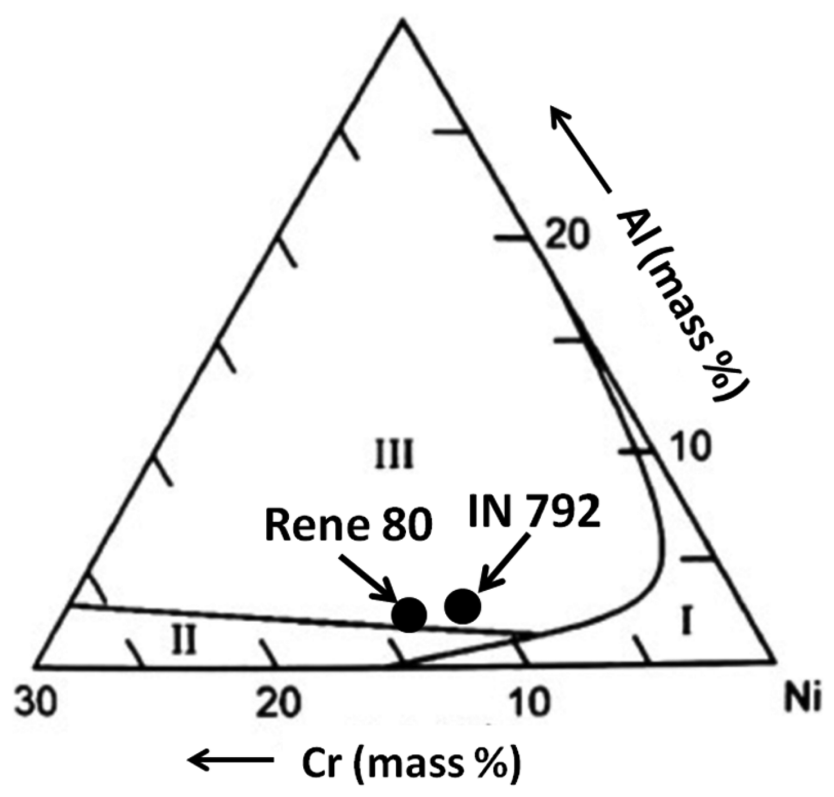

Figure 4: Oxidation map for $\mathrm{Ni}-\mathrm{Cr}-\mathrm{Al}$ alloys [4] showing fields of various oxide scale type formation as function of alloy $\mathrm{Cr}$ and $\mathrm{Al}$ contents at $1,000-1,100^{\circ} \mathrm{C}$ : I-NiO forming alloys, II- $\mathrm{Cr}_{2} \mathrm{O}_{3}$ forming alloys, III- $\mathrm{Al}_{2} \mathrm{O}_{3}$ forming alloys. Superimposed are $\mathrm{Cr}$ and $\mathrm{Al}$ contents of Rene 80 and IN 792.
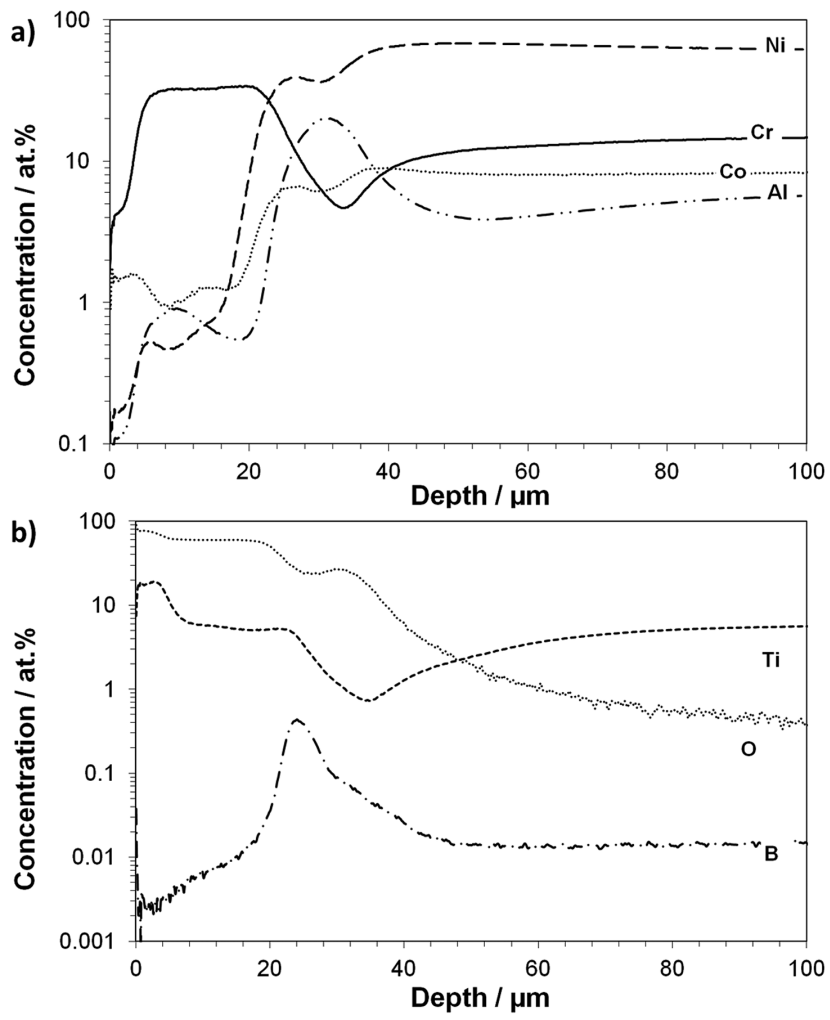

Figure 5: GD-OES depth profiles of Rene 80 after oxidation at $1,050{ }^{\circ} \mathrm{C}$ in $\mathrm{Ar}-20 \% \mathrm{O}_{2}$ for $50 \mathrm{~h}$ showing the depth profiles of (a) major and (b) minor alloying elements. 

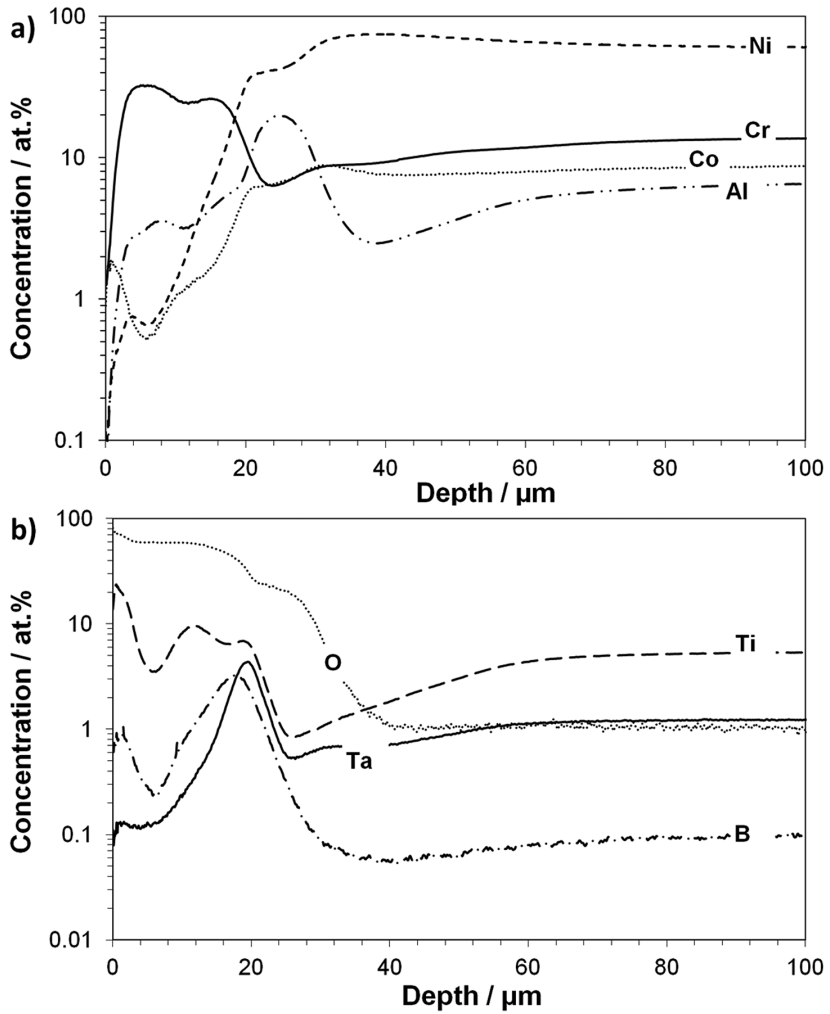

Figure 6: GD-OES depth profiles of IN 792 after oxidation at $1,050^{\circ} \mathrm{C}$ in $\mathrm{Ar}-20 \% \mathrm{O}_{2}$ for $50 \mathrm{~h}$ showing the depth profiles of (a) major and (b) minor alloying elements.

Despite the smaller overall oxide scale thickness, the GD-OES depth profile of IN 792 (Figure 6a and b) is qualitatively similar to the profile obtained for Rene 80. However, different from Rene 80 , at the bottom part of the oxide scale formed on IN 792, co-enrichment of $\mathrm{Ti}$ and $\mathrm{Ta}$ is observed. Moreover, the width of the outer enrichment of Ti is smaller for IN 792 in comparison with Rene 80.

The SEM images showing the cross-section of Rene 80 after oxidation (Figure 7) revealed that the alloy formed a multilayered oxide scale consisting of a continuous layer of $\mathrm{TiO}_{2}$ in the very outer part of the oxide scale below which a $\mathrm{Cr}_{2} \mathrm{O}_{3}$ layer developed. Also a zone of internal oxidation of aluminium is present. These findings fit to the observation by GD-OES. Additionally, the presence of Ti-rich particles embedded into chromia as well as void formation can be observed. This observation strongly indicates rapid outer Ti transport and simultaneous inward transport of vacancies, which agglomerate and form voids.

The SEM image of the cross-section of oxidized IN 792 (Figure 8) shows that the alloy formed an oxide scale

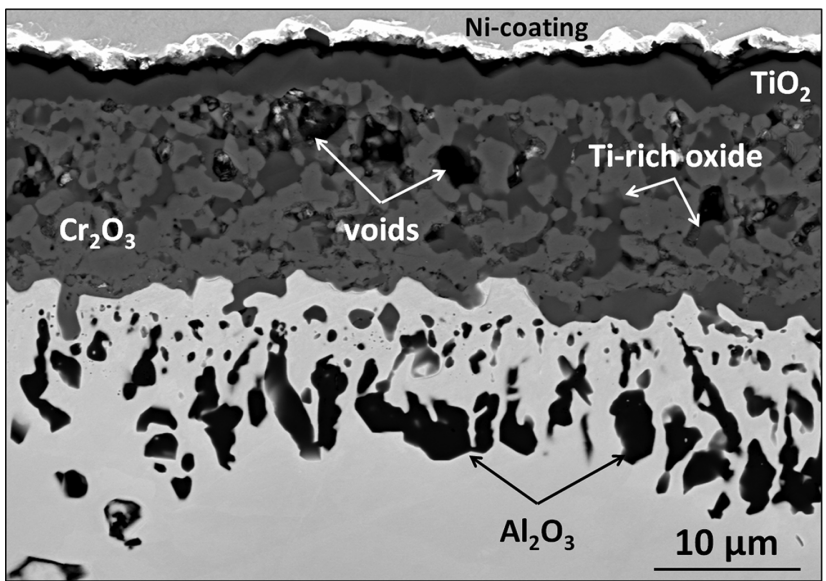

Figure 7: SEM/backscattered electrons(BSE) image showing the cross-section of Rene 80 after isothermal oxidation test at $1,050^{\circ} \mathrm{C}$ for $50 \mathrm{~h}$ in $\mathrm{Ar}-20 \% \mathrm{O}_{2}$.

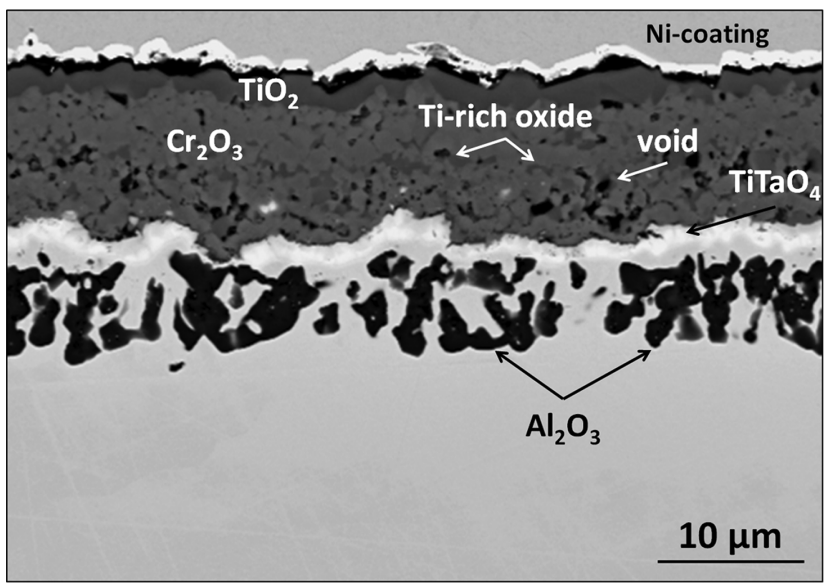

Figure 8: SEM/BSE image showing the cross-section of IN 792 after isothermal oxidation test at $1,050^{\circ} \mathrm{C}$ for $50 \mathrm{~h}$ in $\mathrm{Ar}-20 \% \mathrm{O}_{2}$.

qualitatively similar to that obtained on Rene 80, namely $\mathrm{TiO}_{2}$ formation on top of chromia. A zone of internal oxidation of aluminium is present as well. Contrary to Rene 80, IN 792 formed $\mathrm{TiTaO}_{4}$ at the interface between the oxide scale and the alloy. Formation of such an oxide was found by Jalowicka etal. [8] after air exposure of another Ta-containing Ni-base superalloy PWA1483. It was also shown using model alloys that the addition of Ta into Ti-containing alloy slows down the oxidation kinetics due to formation of $\mathrm{TiTaO}_{4}$ compound, which ties up $\mathrm{Ti}$ and hampers its transport into the chromia scale [8]. In the present work, the alloys were exposed to Ar-20\% $\mathrm{O}_{2}$ atmosphere, which eliminates the formation of stable TiN, which in turn limits free Ti able to diffuse through the chromia scale. Comparison of both alloys 


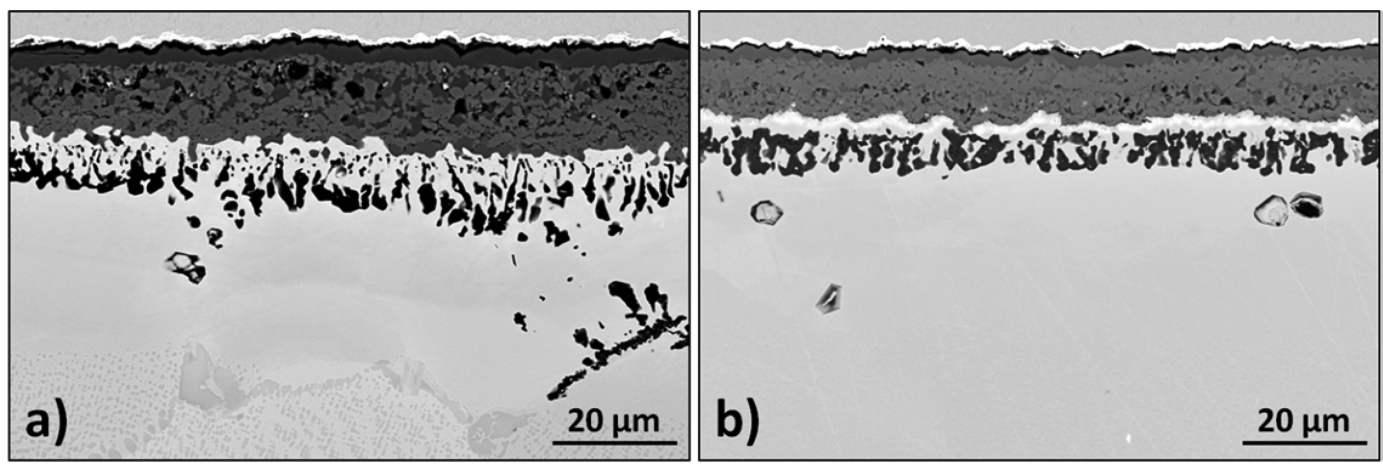

Figure 9: SEM/BSE images showing comparison of the oxides formed on (a) Rene 80 and (b) IN 792 during isothermal oxidation test at $1,050^{\circ} \mathrm{C}$ for $50 \mathrm{~h}$ in $\mathrm{Ar}-20 \% \mathrm{O}_{2}$.

after the exposure (Figure 9) clearly shows that the alloy containing Ta forms a thinner oxide scale. It is visible that in case of $\mathrm{IN} 792$, the outer $\mathrm{TiO}_{2}$ is thinner, and contrary to that formed on Rene 80, it is not a continuous layer. Moreover, the chromia scale is thinner and contains less Ti-rich precipitates as well as voids. Finally, the zone of internal oxidation of $\mathrm{Al}$ is thinner for IN 792 as compared to Rene 80. The results of the thickness measurement of $\mathrm{TiO}_{2}, \mathrm{Cr}_{2} \mathrm{O}_{3}$ and the zone of internal oxidation of $\mathrm{Al}$ are summarized in Table 2. As shown in Table 2, IN 792 formed a $40 \%$ thinner $\mathrm{TiO}_{2}$ oxide layer, $30 \%$ thinner $\mathrm{Cr}_{2} \mathrm{O}_{3}$ and the zone of internal aluminium oxidation is thinner by $40 \%$ compared to Rene 80 .

Table 2: Measured thicknesses $(\mu \mathrm{m})$ of oxide scale layers in outer scale and width of zone containing internal Al-oxide (IOZ).

\begin{tabular}{lrr}
\hline Oxide & Rene 80 & IN 792 \\
\hline $\mathrm{TiO}_{2}$ & $3.07 \pm 0.08$ & $1.74 \pm 0.29$ \\
$\mathrm{Cr}_{2} \mathrm{O}_{3}$ & $13.39 \pm 1.41$ & $9.46 \pm 0.27$ \\
$\mathrm{IOZ}$ & $11.46 \pm 1.79$ & $6.98 \pm 0.56$ \\
\hline
\end{tabular}

\section{Conclusions}

Considering all the findings shown in the present work, it can be concluded that the addition of Ta into Ti-containing $\mathrm{Ni}-\mathrm{Cr}-\mathrm{Al}$ alloys slows down the oxidation kinetics and influences the oxide scale morphology. The investigation performed using GD-OES and SEM showed that the alloy containing $\mathrm{Ti}$ and $\mathrm{Ta}$ forms a $\mathrm{TiTaO}_{4}$ compound near the scale/alloy interface. It seems that the formation of this compound hampers outer $\mathrm{Ti}$ as well as inward oxygen transport. The proof for the latter is thinner outer $\mathrm{TiO}_{2}$ layer and zone of internal oxidation for IN 792. The smaller amount and size of Ti-rich particles and voids in the oxide scale on IN 792 can also support the abovementioned assumption.

Acknowledgements: This work has been supported by theNational Science Centre (NCN) in Poland, decision number 2014/15/B/ST8/00120.

Part of the results was obtained in Institute of Energy and Climate Research (IEK-2) in Forschungszentrum Juelich.

Funding: This work was supported by the National Science Centre (NCN) in Poland; [2014/15/B/ST8/00120].

\section{References}

[1] J.R. Davis, Heat Resistant Materials, ASM Specialty Handbook, ASM International - Materials Park, Ohio (1997).

[2] C. Wagner, Z. El. Ch., 63 (1959) 7 772-782.

[3] S. Mrowec, Z. Grzesik and J. Dabek, High Temp. Mater. Processes, 21 (2002) 87-108.

[4] C.S. Giggins and F.S. Pettit, J. Electrochem. Soc.: Solid State Sci., 118 (1971) 1782-1790.

[5] M. Danielewski, Z. Grzesik and S. Mrowec, Corros. Sci., 53 (2011) 2785-2792.

[6] N. Birks, G.H. Meier and F.S. Pettit, High-Temperature Oxidation of Metals, (2nd Edition), Cambridge University Press, Cambridge (2006).

[7] Z. Jurasz, K. Adamaszek, R. Janik, Z. Grzesik and S. Mrowec, Defect Diffus. Forum, 289-292 (2009) 775-782.

[8] A. Jalowicka, W. Nowak, D. Naumenko, L. Singheiser and W.J. Quadakkers, Mater. Corros., 65 (2014) 178-187.

[9] J.P. Pfeifer, H. Holzbrecher, W.J. Quadakkers and J. Speier, J. Anal. Chem., 346 (1993) 186-191. 
[10] W.J. Quadakkers, A. Elschner, W. Speier and H. Nickel, Appl. Surf. Sci., 52 (1991) 271-287.

[11] W.J. Nowak, J. Anal. At. Spectrom., (2017) DOI:10.1039/ C7JA00069C.

[12] W.J. Nowak, D. Naumenko, A. Jałowicka, D.J. Young, V. Nischwitz and W.J. Quadakkers, Mater. Corros., 68 (2017) 171-185.
[13] W.J. Quadakkers, D. Naumenko, E. Wessel, V. Kochubey and L. Singheiser, Oxid. Met., 61 (2004) 17-37.

[14] D. Monceau and B. Pieraggi, Oxid. Met., 50 (1998) 477-493.

[15] A. Jalowicka, W. Nowak, D.J. Young, V. Nischwitz, D. Naumenko and W.J. Quadakkers, Oxid. Met., 83 (2015) 393-413.

[16] A. Kanjer, V. Optasanu, L. Lavisse, et al., Oxid. Met., (2017) https://doi.org/10.1007/s11085-016-9700-6. 